\title{
Effects of carbon on ion-implantation-induced disorder in GaN
}

\author{
S. O. Kucheyev ${ }^{\text {a) }}$ \\ Lawrence Livermore National Laboratory, Livermore, California 94551, USA \\ J. E. Bradby, C. P. Li, and S. Ruffell \\ Department of Electronic Materials Engineering, The Australian National University, Canberra, Australian \\ Capital Territory 0200, Australia
}

T. van Buuren and T. E. Felter

Lawrence Livermore National Laboratory, Livermore, California 94551, USA

(Received 23 October 2007; accepted 3 December 2007; published online 26 December 2007)

\begin{abstract}
Wurtzite GaN films bombarded with $40 \mathrm{keV} \mathrm{C}$ ions to high doses $\left(5 \times 10^{17}\right.$ and $\left.1 \times 10^{18} \mathrm{~cm}^{-2}\right)$ are studied by a combination of Rutherford backscattering/channeling spectrometry, transmission electron microscopy, and soft x-ray absorption spectroscopy. Results show that, contrary to other ion species, implanted $\mathrm{C}$ forms nitrilelike carbon-nitride bonds $(-\mathrm{C} \equiv \mathrm{N})$ and suppresses ion-beam-induced material decomposition involving the formation and agglomeration of $\gtrsim 5$-nm-large $\mathrm{N}_{2}$ gas bubbles. (C) 2007 American Institute of Physics. [DOI: 10.1063/1.2827587]
\end{abstract}

Carbon is a common impurity in GaN crystals, ${ }^{1}$ and it affects their technologically important electrical and optical characteristics. $^{1-4}$ In addition, $\mathrm{C}$ impurities actively participate in the interaction of radiation defects during ion-assisted processing, such as doping, electrical isolation, and dry etching. ${ }^{5}$ In particular, the presence of $\mathrm{C}$ impurities results in a strong enhancement of the buildup of lattice disorder in ion-irradiated GaN. ${ }^{5}$

During our previous systematic studies, ${ }^{5}$ we noticed that $\mathrm{GaN}$ crystals implanted with high doses of $\mathrm{C}$ ions (resulting in lattice amorphization) were light to dark brown in color, while the samples bombarded by all the other ion species used $\left({ }^{16} \mathrm{O},{ }^{28} \mathrm{Si},{ }^{63} \mathrm{Cu},{ }^{107} \mathrm{Ag},{ }^{197} \mathrm{Au}\right.$, and $\left.{ }^{209} \mathrm{Bi}\right)$ exhibited a much darker color upon amorphization. Stimulated by such a simple but intriguing observation and by the technological importance of understanding properties of $\mathrm{C}$ in group-III nitrides, in this letter, we study $\mathrm{C}$-implanted $\mathrm{GaN}$ and show that $\mathrm{C}$ forms nitrilelike bonds $(-\mathrm{C} \equiv \mathrm{N})$, suppresses the ionbeam-induced material decomposition involving the formation of large $\mathrm{N}_{2}$ gas bubbles, and improves the thermal stability of ion-implantation-amorphized $\mathrm{GaN}^{6}$

The $\sim 2 \mu \mathrm{m}$-thick wurtzite undoped GaN (0001) epilayers used in this study were grown on $c$-plane sapphire substrates by metalorganic chemical vapor deposition at Ledex Corp. (Taiwan). The implantation was carried out at room temperature with $40 \mathrm{keV}{ }^{12} \mathrm{C}^{-}$ions to doses of $5 \times 10^{17}$ and $1 \times 10^{18} \mathrm{~cm}^{-2}$ with a beam flux of $\sim 3 \times 10^{13} \mathrm{~cm}^{-2} \mathrm{~s}^{-1}$, at $\sim 7^{\circ}$ off normal in order to minimize channeling. After implantation, selected samples were processed in a rapid thermal annealer in a proximity geometry (i.e., face to face on $\mathrm{GaN}$ wafers) in an $\mathrm{Ar}$ ambient at atmospheric pressure at temperatures of 500 and $700{ }^{\circ} \mathrm{C}$ for 60 and $30 \mathrm{~s}$, respectively. Depth profiles of lattice disorder and $\mathrm{C}$ atoms were studied by Rutherford backscattering/channeling (RBS/C) spectrometry with $2 \mathrm{MeV}^{4} \mathrm{H}^{+}$ions incident along the [0001] direction and backscattered to $164^{\circ}$. The analysis of RBS spectra was done with stopping powers and scattering cross sections from the RUMP code ${ }^{7}$ with an assumption of a constant atomic density $\left(8.9 \times 10^{22}\right.$ atoms $/ \mathrm{cm}^{3}$, which is the density of single-crystal $\mathrm{GaN}$ ) and the material composition

\footnotetext{
${ }^{a)}$ Electronic mail: kucheyev@1lnl.gov.
}

$\mathrm{GaNC}_{x}$. Selected specimens were studied by cross-sectional transmission electron microscopy (XTEM) with a $300 \mathrm{keV}$ electron beam.

The x-ray absorption near-edge structure (XANES) spectroscopy experiments were performed at undulator beamline 8.0 at the Advanced Light Source. Spectra were obtained by measuring the total electron yield by monitoring sample photocurrent. During XANES measurements, the surface normal of $\mathrm{GaN}$ crystals was at an angle of $40^{\circ}$ relative to the incident $\mathrm{x}$-ray beam axis. The monochromator was calibrated by aligning the main peak in the $\mathrm{N} K$-edge spectrum from $\mathrm{N}_{2}$ gas to $400.90 \mathrm{eV}$. $^{8}$ Reference spectra were also measured from $\mathrm{Ga}_{2} \mathrm{O}_{3}$ powder $(99.99 \%$ purity, Morton Thiokol, Inc.) and a Ga polycrystal (99.999 99\% purity, Johnson Matthey Electronics).

Figure 1 shows RBS/C spectra suggesting complete disordering of the crystal lattice in an $\sim 200$-nm-thick near-

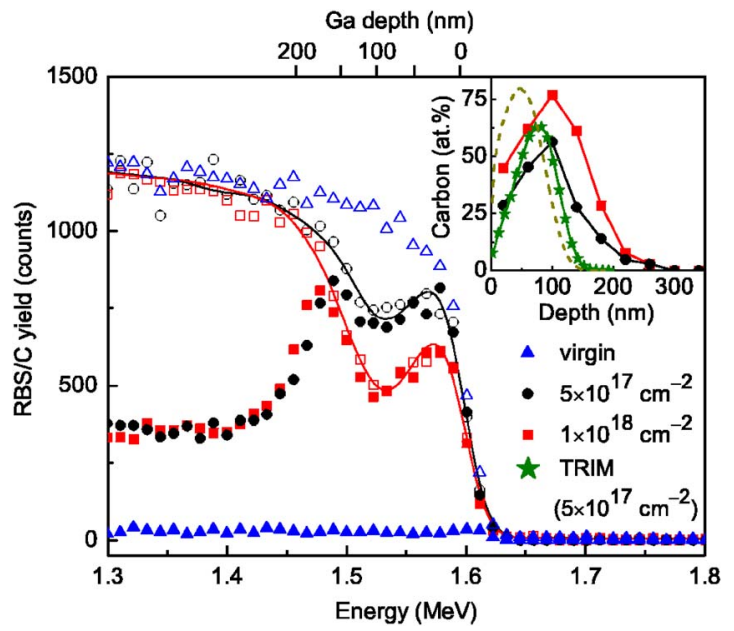

FIG. 1. (Color online) RBS channeling (closed symbols) and random (open symbols) spectra showing the evolution of lattice disorder and $\mathrm{C}$ content in $\mathrm{GaN}$ epilayers bombarded at room temperature with $40 \mathrm{keV} \mathrm{C}$ ions to doses of $5 \times 10^{17}$ and $1 \times 10^{18} \mathrm{~cm}^{-2}$. For clarity, only every third experimental point is shown. Corresponding spectra from unimplanted (virgin) GaN are also shown. Solid lines are results of RUMP simulation. The inset shows $\mathrm{C}$ depth profiles extracted from such RBS spectra as well as profiles of C (stars) and lattice vacancies (dash line) predicted by TRIM simulations for a dose of $5 \times 10^{17} \mathrm{~cm}^{-2}$. The vertical scale of the vacancy profile is arbitrary. 


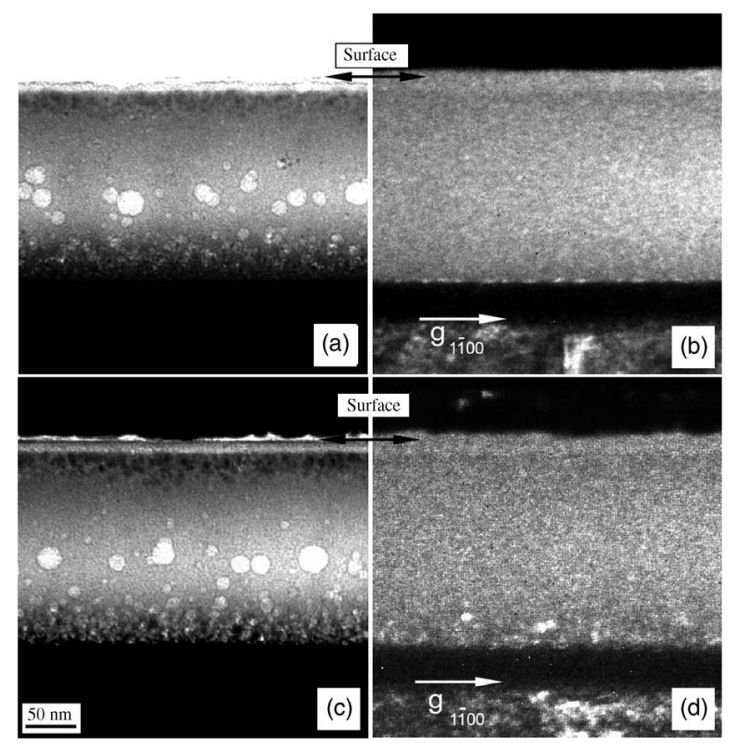

FIG. 2. Bright-field [(a) and (c)] and dark-field [(b) and (d)] XTEM images of GaN samples implanted at room temperature with $40 \mathrm{keV} \mathrm{C}$ ions to a dose of $10^{18} \mathrm{~cm}^{-2}$. An as-implanted sample is shown in (a) and (b), and a sample implanted and subsequently annealed at $500{ }^{\circ} \mathrm{C}$ is shown in (c) and (d). All four images are of the same magnification.

surface region affected by $\mathrm{C}$ ion implantation for both doses of $5 \times 10^{17}$ and $1 \times 10^{18} \mathrm{~cm}^{-2}$. The inset in Fig. 1 shows that the depth profiles of implanted C, extracted from RBS spectra, adequately correlate with predictions of ballistic calculations. ${ }^{9,10}$

The microstructure of samples implanted to a dose of $10^{18} \mathrm{~cm}^{-2}$, before and after annealing at $500{ }^{\circ} \mathrm{C}$, is illustrated in XTEM images in Figs. 2(a)-2(d). A comparison of bright- and dark-field XTEM images from Figs. 2(a) and 2(b) shows that such irradiation results in amorphization of an $\sim 200 \mathrm{~nm}$-thick near-surface layer, consistent with RBS/C data (Fig. 1). The amorphization was also confirmed by selected-area electron diffraction. A band of cavities, $\sim 5-25 \mathrm{~nm}$ in diameter, at depths of $\sim 100-160 \mathrm{~nm}$ from the sample surface is also seen in Fig. 2(a). Previous studies $^{11,12}$ have shown that such large cavities are, in fact, $\mathrm{N}_{2}$ gas bubbles, a product of ion-beam-induced decomposition of GaN upon amorphization. Interestingly, Fig. 2(a) shows that the formation of $\geq 5$-nm-large bubbles occurs mostly at depths $\gtrsim 100 \mathrm{~nm}$, which is beyond the projected range of $40 \mathrm{keV} \mathrm{C}$ ions $\left(R_{p}=72 \mathrm{~nm}\right.$, calculated with the TRIM code $)^{9}$ and is largely suppressed in the first $\sim 100 \mathrm{~nm}$ from the surface, where most nuclear energy loss occurs (see the inset in Fig. 1, showing that the maximum of the vacancy profile is at $R_{p d}=47 \mathrm{~nm}$ ) and where maximum decomposition is typically observed. ${ }^{11,12}$ Hence, implanted $\mathrm{C}$ atoms effectively suppress ion-induced material decomposition. Moreover, the fact that amorphous layer thicknesses measured by RBS/C and XTEM correlate well supports our assumption of constant (atomic) material density used in calculations of the depth scale in RBS/C spectra in Fig. 1. It also strongly suggests a little increase in the amorphous layer thickness associated with ion-induced porosity upon amorphization. This is in contrast to the case of GaN amorphized by heavy $\left({ }^{197} \mathrm{Au}\right)$ ions, for which large volume expansions of up to $\sim 50 \%$ have been reported. ${ }^{11}$

A comparison of Figs. 2(a) and 2(b) with Figs. 2(c) and 2(d) shows that annealing at $500{ }^{\circ} \mathrm{C}$ does not lead to decomposition of the entire implanted layer, in contrast to the case Downloaded 20 Feb 2008 to 150.203.178.117. Redistribution subject
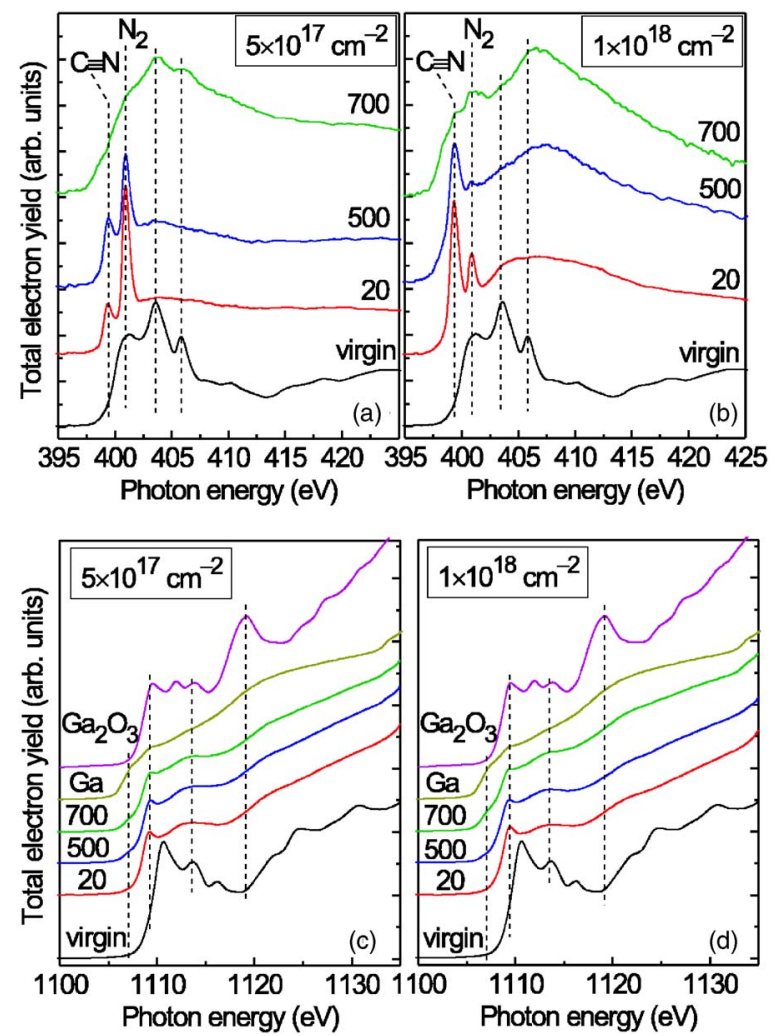

FIG. 3. (Color online) Nitrogen $K$-edge [(a) and (b)] and Ga $L_{3}$-edge [(c) and (d)] XANES spectra from GaN implanted at room temperature with $40 \mathrm{keV} \mathrm{C}$ ions to doses of $5 \times 10^{17}\left[(\mathrm{a})\right.$ and (c)] and $1 \times 10^{18} \mathrm{~cm}^{-2}[(\mathrm{~b})$ and (d)] and annealed at different temperatures, as indicated (in degree Celsius). Spectra from unimplanted $\mathrm{GaN}$ are labeled "virgin." Spectra from $\mathrm{Ga}_{2} \mathrm{O}_{3}$ powder and a Ga metal polycrystal are also shown in (c) and (d).

of GaN amorphized with heavy ions. Indeed, it has previously been shown that, for heavy-ion amorphized GaN, annealing at temperatures above $\sim 400{ }^{\circ} \mathrm{C}$ leads to agglomeration of $\mathrm{N}_{2}$ bubbles and associated exfoliation of the sample surface. ${ }^{11}$ Hence, doping with $\mathrm{C}$ effectively suppresses both the formation of large $\mathrm{N}_{2}$ bubbles during irradiation and bubble agglomeration during annealing at $\sim 500{ }^{\circ} \mathrm{C}$. The microscopy data from Fig. 2 are also consistent with RBS/C results revealing no changes in spectra from as-implanted samples upon annealing at 500 and $700{ }^{\circ} \mathrm{C}$ (spectra not shown).

An insight into chemical bonding in C-implanted $\mathrm{GaN}$ is provided by $\mathrm{N} K$ - and Ga $L_{3}$-edge XANES spectra (Fig. 3), which reflect electron transitions from the $\mathrm{N} 1 s$ and $\mathrm{Ga} 2 p_{3 / 2}$ core levels, respectively, into unoccupied electronic states above the Fermi level. If possible core-hole relaxation and electron correlation effects and higher multipole transitions are ignored, such spectra essentially map N-related $p$-projected (N $K$ edge) and Ga-related $s$ - and $d$-projected ( $\mathrm{Ga} L_{3}$ edge) states in the conduction band.

The N $K$-edge spectra [Figs. 3(a) and 3(b)] show that bombardment to both doses results in smearing of all the bands characteristic of virgin $\mathrm{GaN}$ and in the appearance of two relatively narrow peaks centered on 399.4 and $400.9 \mathrm{eV} .{ }^{13}$ In previous XANES studies of ion-implanted $\mathrm{GaN}$, the peak at $400.9 \mathrm{eV}$ has been attributed to $\mathrm{N}$ dangling bonds. ${ }^{14,15}$ We find this assignment unlikely primarily because XANES has a relatively poor sensitivity to pointdefect-induced electronic states. ${ }^{16-18}$ Instead, we assign this peak to molecular nitrogen $\left(\mathrm{N}_{2}\right)$ trapped in a Ga-rich matrix. to AIP license or copyright; see http://apl.aip.org/apl/copyright.jsp 
This assignment is supported by the facts that (i) the peak position, intensity, and width are consistent with the behavior of the peak related to $\mathrm{N}_{2}$ in the gas phase ${ }^{8}$ and (ii) it seems to appear only after lattice amorphization, ${ }^{14}$ consistent with the behavior of ion-beam-induced material decomposition with the formation of large $\mathrm{N}_{2}$ gas bubbles, which also occurs only upon lattice amorphization. ${ }^{11}$

Figures 3(a) and 3(b) show that annealing at $500{ }^{\circ} \mathrm{C}$ reduces the intensity of the $\mathrm{N}_{2}$-related peak at $400.9 \mathrm{eV}$ for both ion doses, suggesting gas loss during annealing. The $\mathrm{N}$ $K$-edge spectra for $700{ }^{\circ} \mathrm{C}$-annealed samples in Figs. 3(a) and 3(b) are broadened versions of the spectrum for unimplanted GaN with an additional lower-energy shoulder at $\sim 398.5 \mathrm{eV}$ and a broad band centered on $\sim 407 \mathrm{eV}$ (which intensity increases with increasing $\mathrm{C}$ dose). This is consistent with a scenario when, at $700{ }^{\circ} \mathrm{C}, \mathrm{N}_{2}$ gas bubbles agglomerate and burst at the surface, while the matrix experiences (imperfect) polycrystallization. ${ }^{11}$

We assign the other narrow peak at $399.4 \mathrm{eV}$ in $\mathrm{N}$ $K$-edge spectra of C-implanted GaN to nitrilelike carbonnitride bonds $(-\mathrm{C} \equiv \mathrm{N})$. This assignment is based on the observations that (i) the peak position corresponds to nitrilelike bonds (rather than pyridine-or graphiticlike bonds) $;{ }^{19}$ (ii) the peak is intense and relatively narrow, consistent with predominantly $\pi$-character of the nitrile bond and previous XANES studies of compounds with such bonds; $;^{19}$ (iii) its intensity increases with increasing $\mathrm{C}$ dose [Figs. 3(a) and 3(b)]; (iv) this peak is absent for GaN implanted with other ion species such as $\mathrm{O}, \mathrm{Mg}, \mathrm{Si}, \mathrm{Ar}$, and $\mathrm{Au} ;{ }^{14,15,20}$ and (v) equivalent peaks are not observed in the $\mathrm{Ga} s$ - and $d$-projected density of states probed in the Ga $L_{3}$-edge spectra, as shown in Figs. 3(c) and 3(d) and discussed below.

Figures 3(c) and 3(d) show that C-ion bombardment dramatically changes the $\mathrm{Ga} L_{3}$ edge, with very minor differences between spectra for samples implanted to different doses. This suggests minor C-Ga bonding, if any. ${ }^{21}$ Data from Figs. 3(c) and 3(d) also strongly suggest that both asimplanted and annealed samples have negligible content of $\mathrm{Ga}_{2} \mathrm{O}_{3}$ oxide since the intense oxide-related peak at $\sim 1119 \mathrm{eV}$ is absent in the corresponding spectra. In addition, Figs. 3(c) and 3(d) provide evidence of stoichiometric imbalance with the formation of $\mathrm{Ga}-\mathrm{Ga}$ metallic bonds since the bands at $\sim 1107.0,1109.2$, and $1113.5 \mathrm{eV}$ (indicated by vertical dash lines in the figure), characteristic of metallic $\mathrm{Ga}$, are observed in the spectra of ion implanted and annealed samples. These observations of $\mathrm{N}$ loss are consistent with previous reports ${ }^{5,12}$ and may support a scenario that stoichiometric imbalance is required for the stability of an amorphous phase of GaN. ${ }^{5,22}$

In summary, we have demonstrated that $\mathrm{C}$ implanted into GaN effectively suppresses ion-beam-induced material decomposition and improves the thermal stability of $\mathrm{GaN}$ heavily disordered by ion bombardment. Our XANES results have provided evidence that $\mathrm{GaN}$ amorphized by $\mathrm{C}$ ion bombardment has nitrilelike $-\mathrm{C} \equiv \mathrm{N}$ bonds and molecular nitrogen $\left(\mathrm{N}_{2}\right)$ trapped in a Ga-rich matrix. These results provide better understanding of the effects of impurities on radiation damage processes and could point to alternative ways to stabilize an amorphous phase of GaN.

The authors thank G. Li for providing GaN wafers. Work at LLNL was performed under the auspices of the U.S. DOE by LLNL under Contract No. DE-AC52-07NA27344. Work at the ANU was supported by the ARC. The ALS is supported by the Director, Office of Science, Office of BES, Materials Sciences Division, of the U.S. DOE under Contract No. DE-AC03-76SF00098 at LBNL.

${ }^{1}$ See, for example, reviews by S. J. Pearton, J. C. Zolper, R. J. Shul, and F. Ren, J. Appl. Phys. 86, 1 (1999); M. A. Reshchikov and H. Morkoc, ibid. 97, 061301 (2005).

${ }^{2}$ A. Castaldini, A. Cavallini, and L. Polenta, Appl. Phys. Lett. 87, 122105 (2005).

${ }^{3}$ S. O. Kucheyev, M. Toth, M. R. Phillips, J. S. Williams, C. Jagadish, and G. Li, J. Appl. Phys. 91, 5867 (2002).

${ }^{4}$ J. Mickevicius, R. Aleksiejunas, M. S. Shur, S. Sakalauskas, G. Tamulaitis, Q. Fareed, and R. Gaska, Appl. Phys. Lett. 86, 041910 (2005).

${ }^{5}$ S. O. Kucheyev, J. S. Williams, C. Jagadish, J. Zou, and G. Li, Phys. Rev. B 62, 7510 (2000); S. O. Kucheyev, J. S. Williams, C. Jagadish, J. Zou, G. Li, and A. I. Titov, ibid. 64, 035202 (2001); S. O. Kucheyev, J. S. Williams, J. Zou, G. Li, C. Jagadish, and A. I. Titov, Nucl. Instrum. Methods Phys. Res. B 190, 782 (2002).

${ }^{6}$ Such a suppression of material decomposition explains the difference in sample color if the black color of amorphous $\mathrm{GaN}$ is related to ion-beaminduced material decomposition with the formation of $\mathrm{N}_{2}$ gas bubbles embedded in a Ga-rich matrix.

${ }^{7}$ L. R. Doolittle, Nucl. Instrum. Methods Phys. Res. B 9, 344 (1985).

${ }^{8}$ Reference spectra of $\mathrm{N}_{2}$ in the gas phase were measured from a $\mathrm{ZnO}$ sample containing large (over several microns in diameter) $\mathrm{N}_{2}$ gas bubbles. This calibration sample was provided by J. Denlinger from Lawrence Berkeley National Laboratory.

${ }^{9}$ Ballistic calculations of the profiles of atomic displacements and implanted $\mathrm{C}$ atoms were performed with the TRIM code (version SRIM2003.26) (Ref. 10).

${ }^{10}$ J. F. Ziegler, J. P. Biersack, and U. Littmark, The Stopping and Range of Ions in Solids (Pergamon, New York, 1985), Vol. 1, p 109.

${ }^{11}$ S. O. Kucheyev, J. S. Williams, C. Jagadish, V. S. J. Craig, and G. Li, Appl. Phys. Lett. 77, 1455 (2000); S. O. Kucheyev, J. S. Williams, J. Zou, C. Jagadish, and G. Li, ibid. 77, 3577 (2000).

${ }^{12}$ W. Jiang, Z. Zhang, and W. J. Weber, Appl. Phys. Lett. 89, 021903 (2006).

${ }^{13}$ The energy positions and intensities of the two narrow peaks at 399.4 and $400.9 \mathrm{eV}$ in $\mathrm{N} \mathrm{K}$-edge spectra of $\mathrm{C}$-implanted samples are independent of the sample orientation relative to the incident $\mathrm{x}$-ray beam axis. However, for unimplanted $\mathrm{GaN}$ samples, the intensities of the major peaks in $\mathrm{N}$ $K$-edge spectra and the position of the peak at $\sim 1113.7 \mathrm{eV}$ in Ga $L_{3}$-edge spectra exhibit an angular dependence.

${ }^{14}$ M. Katsikini, F. Pinakidou, E. C. Paloura, and W. Wesch, Appl. Phys. Lett. 82, 1556 (2003).

${ }^{15}$ P. N. K. Deenapanray, M. Petravic, K. J. Kim, B. Kim, and G. Li, Appl. Phys. Lett. 83, 4948 (2003).

${ }^{16}$ Although an accurate quantitative evaluation of XANES sensitivity to defect-related states is not straightforward and requires calculation of the transition matrix elements and the densities of states involved, XANES is generally sensitive to concentrations of defects comparable to the atomic concentration in the material. Indeed, the signal from defects is detected when the density of defect-related electronic states is roughly comparable to the density of states in the conduction band. Such a large concentration of ion-beam-produced point defects is unlikely since, for most semiconductors, with a local concentration of point defects of even $\sim 10$ at $\%$, the energy of the defective lattice would exceed that of the amorphous phase, making such a defective lattice energetically unfavorable. (Ref. 17) For an additional discussion of defect studies with XANES, see, for example, Ref. 18.

${ }^{17}$ J. A. Davis, in Ion Implantation and Beam Processing, edited by J. S. Williams and J. M. Poate (Academic, Sydney, 1984), p. 81.

${ }^{18}$ S. O. Kucheyev, C. Bostedt, T. van Buuren, T. M. Willey, T. A. Land, L. J. Terminello, T. E. Felter, A. V. Hamza, S. G. Demos, and A. J. Nelson, Phys. Rev. B 70, 245106 (2004).

${ }^{19}$ See, for example, N. Hellgren, J. Guo, C. Sathe, A. Agui, J. Nordgren, Y. Luo, H. Agren, and J. E. Sundgren, Appl. Phys. Lett. 79, 4348 (2001); and references therein.

${ }^{20} \mathrm{~S}$. O. Kucheyev (unpublished).

${ }^{21}$ In addition to $\mathrm{C}-\mathrm{N}, \mathrm{C}-\mathrm{Ga}$, and $\mathrm{Ga}-\mathrm{Ga}$ bonding studied here, $\mathrm{C}-\mathrm{C}$ bonds could also exist in $\mathrm{C}$-implanted $\mathrm{GaN}$. Possible formation of such $\mathrm{C}-\mathrm{C}$ bonds requires further studies.

${ }^{22}$ S. O. Kucheyev, J. S. Williams, J. Zou, and C. Jagadish, J. Appl. Phys. 95, 3048 (2004). 